\title{
Predictive Factors of Therapeutic Response According to Craniofacial Skeletal Biotype in Patients with Sleep Apnoea Syndrome using Mandibular Advancement Devices: A Pilot Study
}

\section{Rafael Ecija Navarro}

Central Military University Hospital "Gomez Ulla"

\section{Berşan Karadede}

Izmir Katip Çelebi University

Beyza Karadede Ünal ( $\sim$ dr.beyzakaradede@gmail.com )

Izmir Katip Çelebi University

Domingo Martin Salvador

Visiting professor Complutense University

\section{Research Article}

Keywords: occlusal splints, sleep apnoea syndrome, growth, polysomnography, face, cephalometry

Posted Date: September 29th, 2021

DOI: https://doi.org/10.21203/rs.3.rs-887763/v1

License: (c) (i) This work is licensed under a Creative Commons Attribution 4.0 International License. Read Full License 


\section{Abstract}

Background: In the scientific literature, there is no consistency of results regarding the effectiveness of mandibular advancement devices (MADs) for sleep apnoea treatment. We have considered facial growth as an important predictor of treatment. In this study we analysed that how facial biotype can influence the therapeutic effect of MADs according to polysomnographic records in SAHS patients.

Methods: The study enrolled 46 patients with mild to moderate SAHS diagnosed by a polysomnographic test. Using cephalometry, we classified all the patients according their facial biotype (mesofacial, brachyfacial or dolichofacial). ShapiroWilk test was used to choose the parametric or non-parametric tests. The quantitative variables were described with the arithmetic mean with its standard deviation or the median with its interquartile range. The hypothesis tests used were Pearson's chi-squared test, paired sample Student's t test, the Wilcoxon test, one-way ANOVA, Kruskal-Wallis test and Mann-Whitney U test. A $p<0.05$ was considered statistically significant.

Results: The respiratory disturbance index (RDI) results were: brachyfacial patients had a reduction to 15 events/hour ( $p<$ $0.001)$, the mesofacial patients had a reduction to 14 events/hour $(p<0.001)$ and the dolichofacial patients did not show a significant reduction in the RDI. The oxygen desaturation index (ODI) results were as follows: brachyfacial patients had a reduction in ODI episodes to 45 episodes/hour $(p=0.001)$, mesofacial patients had a reduction to 18 episodes/hour $(p=0.001)$. The dolichofacial patients did not show a reduction in this index. As far as the number of arousals, in the brachyfacial group, the number of awakenings with MAD therapy was reduced to 23 events/hour $(p=0.003)$, while in the mesofacial group, it was reduced to 37 episodes/hour $(p=0.012)$. The same behaviour was observed in the dolichofacial group, did not have a reduction in the number of awakenings during sleep after MAD therapy.

Conclusions: The facial biotype influences the effectiveness of MAD therapy and is considered a good predictive factor. Dolichofacial patients failed to obtain a significant result in the polysomnographic records using a MAD for sleep apnoea treatment.

\section{Introduction}

Sleep apnoea-hypopnoea syndrome (SAHS) is characterized by a repeat collapse of the upper airway during sleep, causing intermittent hypoxia and disturbances with fragmentation of sleep[1].

Nasal continuous positive pressure (CPAP) in the upper airway is the gold standard and first choice of treatment in patients with moderate to severe symptomatic SAHS[2]. Intraoral mandibular advancement devices (MADs) are indicated in patients with night time snoring and mild to moderate SAHS. MADs are less effective than CPAP, but patients show more acceptance and compliance in their use at night. However, until now, few studies have analysed MAD prognostic factors that predict response or failure after their application, and there is a lack of quorum on it[3]. A recent study by Sutherland et all[4] focused on verifying the craniofacial influence on the response of MADs in awake patients, having found no conclusive results as a predictive factor in MAD therapy.

The efficacy of MADs is not predictable and uncertain[5], and more studies are needed to obtain the best therapy for SAHS patients[6]. The objective of this study is to evaluate how facial biotype can influence the therapeutic effect of MADs according to polysomnographic records $n$ patients diagnosed with mild to moderate SAHS.

\section{Methods}

The study was performed a posteriori, once the patients were diagnosed and treated. This research was performed by the Departments of Pulmonology, Neurophysiology, Otorhinolaryngology, Radiology and Odontology that make up the Sleep Unit of the Gómez Ulla Central Defense Military Hospital (HCD). This study is a retrospective, observational longitudinal study and was 
approved by the ethical committee in the same institution with number 49/18. All methods used in this study were performed in accordance with the Declaration of Helsinki. Patient gave their written consent to be treated with MADs, knowing their long-term side effects and that their data could be used for the elaboration of future studies.

The sample was made up of patients with the health insurance of the Spanish armed forces (ISFAS). Patietns were reffered to the Dentistry Department of the HCD, after being diagnosed with mild to moderate SAHS, for MAD theraphy.

Consecutive non-probabilistic sampling. A total of 46 patients, of both sexes, without age limits, were recruited. They were diagnosed with mild to moderate SAHS by previously conducted polysomnography (PSG).

Patients who were diagnosed with severe SAHS by PSG, a central component of SAHS, comorbidities of cardiovascular diseases, presence of any sign or symptom of temporomandibular joint pathology, active periodontal disease with loss of major bone support in $50 \%$ of teeth per hemiarcade, absence of more than $50 \%$ of teeth per hemiarcade, lateral radiographs of the skull in a state of dental non-occlusion and where the hyoid bone could not be observed.

Patients participating in the study underwent a lateral X-ray of the skull, in the natural position of the head and in dental occlusion, with the Instrumentarium ORTHOPANTOMOGRAPH OP300 (Finland). The natural position of the head was obtained following the methodology described by Moorees and Kean in 1958[7]. A cephalometric study was carried out where the craniofacial structure was examined, and patients were classified according to their facial biotype. The cephalometric study was carried out and analysed by the same person, and the measurements were made using Dolphin imaging ${ }^{\circledR}$ cephalometric diagnostic software, Chatsworth; CA, U.S.A; through which the cephalometric prescription FACE $®$ was used. Jarabak's spheres of percentage were analysed, wich was determined thanks to the average obtained between the anterior facial height (nasionmenton distance) and posterior facial height (sella-gonion distance) The final result of the classification of the 46 patients was, according to this methodology, brachyfacial $(n=16)$, mesofacial $(n=14)$ and dolichofacial $(n=16)$.

The brachyfacial pattern shows hypodivergent growth, where the lower facial height is decreased, being represented in the 64$80 \%$ interval. (Fig. 1.)

The dolichofacial pattern is characterized by hyperdivergent, where the anterior facial height is increased, being represented in the 54-58\& interval. (Fig. 2.)

The mesofacial skeletal pattern is one whose growth is within normal patterns, being represented in the $59-63 \%$ interval. (Fig. 3.)

The cephalometric points used in the study were: (Fig. 4.)

The device in our study was made with two independent splints that are fused with acrylic and two lateral unidirectional screws that classifies this kind of MAD as an adjustable advance type. (Fig. 5.)

This device is dental supported, and the splints must be made extending 3 to $5 \mathrm{~mm}$ beyond the dental equator to avoid dental side effects [8]. The constructive bite to advance the mandible was the same in all groups of patients. It was $70 \%$ of the protrusive maximum and was carried out using the George Gauge.

The patients were instructed on how to place the MAD intraorally and had at least a 3 month trial period to adjust to the MAD before performing the second polysomnographic test.

All patients had an initial polysomnographic study that diagnosed mild to moderate SAHS. The PSG system used in this study was the NET-BEACON.

The MAD therapeutic validation examination was carried out by means of a second nightly polysomnographic examination. Finally, we had two PSG recording, the first one was the diagnosis and the second one was to check the therapeutic effect of the MAD. The following PSG parameters were evaluated: 
- Respiratory Disturbance Index (RDI) is the number of apnoeas and hypopnoeas per hour, along with the respiratory efforts associated with micro awakening. The patient is classified as mild if they have 5 to 14 events per hour, moderate if they have 15 to 30 events per hour and severe if they have more than 30 events per hour. The MAD treatment success rate was established to achieve a reduction in the $\mathrm{RDI}$ to a value $<10$ and $>50 \% \mathrm{RDI}$ reduction compared with baseline.

- Oxygen desaturation index (ODI) is the number of episodes of oxygen desaturation at least $4 \% /$ hour.

- Number of arousals or awakenings are brief alerts of the brain that interrupt the structure of dreams, without having to wake up the subject. Thy are detected through the EEG.

Shapiro-Wilk test was used to choose the parametric or non-parametric tests. The quantitative variables were described with the arithmetic mean with its standard deviation or the median with its interquartile range. We used the absolute and relative frequencies (\%) for qualitative variables. The hypothesis tests used were Pearson's chi-squared test, paired sample Student's $t$ test, the Wilcoxon test, one-way ANOVA, Kruskal-Wallis test and Mann-Whitney U test. A $p<0.05$ was considered statistically significant. Data were analysed using the Statistical Package for Social Sciences (SPSS), version 25 for Windows (Chicago, IL, USA). Consecutive non-probabilistic sampling was chosen.

\section{Results}

The mean age in each facial biotype was between 53 and 66 years old, with no significant differences between them. We found the same for body mass index (BMI), neck circumference (NC), and sex. The distribution of these characteristics was homogeneous among the three groups under study. (Table 1)

Table 1

Variable Distribution According to Facial Biotype.

\begin{tabular}{|lllll|}
\hline & \multicolumn{5}{c|}{ Facial Biotype } & \\
\cline { 2 - 5 } & Brachyfacial $\mathbf{n = 1 6}$ & Dolichofacial $\mathbf{n = 1 6}$ & Mesofacial $\mathbf{n = 1 4}$ & $\mathbf{p}$ \\
\hline Age (years) & $66,4(6,5)$ & $59,4(9,1)$ & $53,6(12,5)$ & $0,064^{\star}$ \\
\hline BMl (kg/m²) & $26,6(2)$ & $28,7(2,6)$ & $27,1(3,4)$ & $0,257^{\star}$ \\
\hline Neck circumference & $37,3(3)$ & $40(3,2)$ & $39(2,5)$ & $0,165^{*}$ \\
\hline$(\mathrm{cm})$ & & & & \\
\hline Sex v/m & $11 / 5$ & $13 / 3$ & $10 / 4$ & $0,700^{* *}$ \\
\hline
\end{tabular}

\section{RDI}

Brachyfacial produced a reduction in RDI by 15 events/hour $(p<0.001)$ and by 14 events/hour $(p<0.001)$ in mesofacial group. Dolichofacial did not show a significant reduction in RDI. (Table 2)

Table 2

Polysomnographic Data PrePost MAD treatment in SAHS Patients According to Facial Biotype.

\begin{tabular}{|llllllllll|}
\hline \multicolumn{1}{|c}{ RDI } & \multicolumn{3}{c}{ ODI } & \multicolumn{3}{c|}{ Arousals } \\
\hline & No MAD & MAD & $\mathrm{p}$ & No MAD & MAD & $\mathrm{p}$ & No MAD & MAD & $\mathrm{p}$ \\
\hline Brachyfacial & $28.7(18.6)$ & $13.9(9.8)$ & $<0.001 *$ & $66.5(102)$ & $21(31)$ & $<0,001 * *$ & $107.3(57.3)$ & $84.3(60)$ & 0.0 \\
\hline Dolichofacial & $16(26)$ & $36(34)$ & $0.438 * *$ & $36(34)$ & $19(49)$ & $0.426 * *$ & $67.7(43)$ & $68(37)$ & 0.9 \\
\hline Mesofacial & $18.7(10)$ & $4.9(3.2)$ & $\mathbf{0 . 0 0 1 *}$ & $23.5(23.5)$ & $5(9.75)$ & $\mathbf{0 . 0 0 1 * *}$ & $72.5(110.5)$ & $35.5(70.1)$ & 0.01 \\
\hline * t Student paired samples ** Test Wilcoxon & & & & & & \\
\hline
\end{tabular}




\section{ODI}

Brachyfacial reduced ODI by 45 episodes/hour $(p=0.001)$ and mesofacial by 18 episodes/hour $(p=0.001)$. Dolichofacial did not show a reduction in ODI. (Table 2)

\section{Number of arousals or awakenings}

Brachyfacial group had a reduction in the number of awakenings by 23 events/hour $(p=0.003)$. Mesofacial had a reduction by 37 episodes/hour $(p=0.012$ ). Dolichofacial did not have a reduction in the number of awakenings during sleep. (Table 2$)$

\section{MAD response reduction percentage}

The result obtained in the number of arousals was not significant, but we did find a significant reduction in both RDI and ODI.

Brachyfacial had a reduction in the RDI of $57 \%$ and a reduction in the ODI of $60 \%$. Mesofacial patients had the greatest percentage of decrease in the RDI of $73 \%$ and a reduction in the ODI of $75 \%$. The dolichofacial patients obtained the smallest decrease in the polysomnographic variables, with a reduction in the RDI of $22 \%$ and a reduction in ODI of $19 \%$. (Table 3 )

Table 3

Percentage of response in polysomnographic records according to facial biotype.

\begin{tabular}{|lllll|}
\hline & Brachyfacial & Dolichofacial & Mesofacial & p \\
\hline Arousals reduction \% & $25(21)$ & $23,3(80)$ & $30(31,1)$ & $\mathrm{NS}^{*}$ \\
\hline RDI reduction \% & $57,3(23,5)$ & $22(67)$ & $73(17)$ & $0,001^{* \star}$ \\
\hline ODI reduction \% & $60,5(23)$ & $18,8(174)$ & $75,6(35)$ & $0,002^{* \star}$ \\
\hline *ANOVA; ${ }^{* *}$ Kruskal Wallis & & & & \\
\hline
\end{tabular}

Using the Kruskal-Wallis test, we showed that there was a significant response difference between skeletal patterns in the RDI and ODI. (Table 4)

Table 4

Kruskal-Wallis Test. RDI and ODI

\begin{tabular}{|lll|}
\hline Porc_reducion_R DI & & Porc_reducion_D ESAT \\
\hline H de Kruskal-Wallis & 14,334 & 12,202 \\
\hline gl & 2 & 2 \\
\hline Sig. asintótica &, 001 &, 002 \\
\hline
\end{tabular}

Mesofacial patients obtained a greater reduction in the RDI, $16 \%$ greater than brachyfacial patients and $51 \%$ greater than dolichofacial patients. Brachyfacial patients had an improvement in RDI of 35\% compared to dolichofacial patients. Mesofacial had an improvement in ODI 15\% greater than brachyfacial patients and $56.8 \%$ greater than dolichofacial patients. Brachyfacial patients had a reduction in ODI $41.7 \%$ greater than dolichofacial patients. (Table 5.) 
Table 5

Comprasion Of Percentage Of Polysomnographıc Response To MAD In Each Facial Biotype

\begin{tabular}{|lllllll|}
\hline & $\begin{array}{l}\text { Brachyfacial Vs } \\
\text { Dolichofacial }\end{array}$ & $\mathbf{p}^{*}$ & $\begin{array}{l}\text { Brachyfacial Vs } \\
\text { Mesofacial }\end{array}$ & p* & $\begin{array}{l}\text { Mesofacial Vs } \\
\text { Dolichofacial }\end{array}$ & $\mathbf{p}^{*}$ \\
\hline Subtrat RDI reduction & $35 \%$ & 0.029 & $-16 \%$ & 0.007 & $51 \%$ & 0001 \\
\hline Subtract ODI reduction \% & $41.7 \%$ & 0.004 & $-15.2 \%$ & 0.049 & $56.8 \%$ & 0.001 \\
\hline *Mann Whitney test & & & & & & \\
\hline
\end{tabular}

\section{Discussion}

The meta-analysis performed by the American Academy of Sleep Medicine included 34 studies with a total of more than 1300 patients. The most striking was that, in only four studies, MAD therapy reduced the AHI to below 5 events/hour[5]. These results are considered far from reaching the therapeutic range of healing. Compared with CPAP in the study carried out by Gagnadoux et al[9], MAD therapy reduced the AHI to below 5 events/hour in $42.8 \%$ of patients, while CPAP achieved it in $73.2 \%$ of patients. Treatment with MAD have shown poorer and not predictable efficacy when compared to CPAP therapy[10].

Many research papers advise on the importance of increasing the study to find predictive factors that may influence MAD treatment[11]. Today, exists a great controversy in the scientific literature about the influence of the craniofacial stracture as a predictive factor in the treatment of SAHS with a $\operatorname{MAD}[12,13]$.

The results obtained in our study explained how mesofacial and brachyfacial patients, obtained a significant reduction in all polysomnographic parameters. In contrast, dolichofacial craniofacial growth, did not significantly reduce all these polysomnographic variables. Knowing in advance the small number and the non-homogeneity of our sample, we have carried out an in-depth statistical examination to analyse the reduction percentage of each facial biotype according to the polysomnographic variables. Those who obtained the most significant reduction in the RDI and ODI were the mesofacial and brachyfacial group.

In the study of Guarda-Nardini et al[14] we found similar results with ours. The most common anatomical characteristics that these authors consider to be responsible for a negative response to MAD belong to the dolichofacial group: high mandibular plane angle and an increased anterior facial height. In relation to brachyfacial and mesofacial patients, a shorter facial height is considered a good prognostic factor for MAD treatment[15-17].

On the other hand, our results are conflicting with other investigations that observed that dolichofacial obtained a better response in reducing the $A H I$ by using MAD therapy[18-20].

Our results could be explained in the study of Woods et al[21], the authors showed how mesofacial and brachyfacial patients have more sagittal projection of the lower jaw than dolichofacial. These patients have the mandible further down and back[22], increasing the airway resistance, having a poor prognosis for MAD treatment and a higher risk for SAHS[23]. It has repercussions in the mandibular dynamics, in the protrusion it moves more downward and back, affecting other structures like hyoid bone[24]. It was observed how dolichofacial SAHS patients possess the hyoid bone in a more caudal position[25], being considered a bad prognostic factor. When the distance of it to the mandibular plane is reduced, the AHI obtains a greater decrease using the MAD[26].

Patients presenting any previous signs or symptoms of temporomandibular joint (TMJ) dysfunction, MAD treatment is contraindicated[27]. Joint pain in TMJ is a usual side effect that can appear in up to $33 \%$ of patients undergoing MAD treatment[19,28]. Dolichofacial are more susceptible to having problems in the TMJ[29], because they use to have a shorter mandibular branch and this has been described in patients with SAHS[24]; so it would not be highly recommended that they undergo a MAD treatment. It would be recommended to look for other alternative therapies that may be more effective, such as CPAP or SAHS orthognathic surgery[30]. 
The limitations of the study may be related to the number of patients studied and it not being a multicentre study and find enough patients treated with MAD belonging to the same skeletal SAHS group in order to make the sample balanced.

\section{Conclusions}

The craniofacial skeletal pattern in patients with SAHS influences the efficacy of the MAD, being a predictive factor for its efficacy. The MAD modified the efficacy in reducing the number of apnoeas in SAHS patients with a mesofacial or brachyfacial skeletal structure. In contrast, dolichofacial SAHS patients did not respond significantly to treatment with the MAD, and other therapeutic alternatives should be considered for this group of patients.

\section{Abbreviations}

MAD

Mandibular advancement device

SAHS

Sleep apnoea-hypopnoea syndrome

RDI

Respiratory disturbance index

ODI

Oxygen desaturation index

CPAP

Continuous positive pressure

HCD

Central Defense Military Hospital

ISFAS

Health insurance of the Spanish armed forces

PSG

Polysomnography

SPSS

Statistical Package for Social Sciences

BMI

Body mass index

NC

Neck circumference

$\mathrm{AHI}$

?

TMJ

Temporomandibular joint

\section{Declarations}

Acknowledgments: Thanks to Villar Blanco I., Guiterrez Ortega C., Callol L., Jareno Esteban J. For their knowledge and advices

Authors' contributions: REN analyzed and interpreted the patient data of the radiological and polysomnographic records of treatment. KB was a major contributor in writing the manuscript, KUB managed the study with knowledge about the illness and MD was the ideologist of this study.

Ethics approval and consent to participate: This study is a retrospective, observational longitudinal study and was approved by the ethical committee in the Gómez Ulla Central Defense Military Hospital (HCD) institution with number 49/18. 
Consent for publication: All the patients gave their informed written consent to be treated with MADs, knowing their long-term side effects and that their data could be used for the elaboration of future studies.

Availability of data and materials: The datasets generated and/or analysed during the current study are not publicly available due to patient privacy but are available from the corresponding author on reasonable request.

Competing interests: The authors declare that they have no competing interest.

Funding: This study has received no financial support.

\section{References}

1. Taylor, D. J. et al. Sleep problems in active duty military personnel seeking treatment for post-traumatic stress disorder: presence, change, and impact on outcomes., https://doi.org/10.1093/sleep/zsaa065 (2020).

2. De Vito, A. et al. European position paper on drug-induced sedation endoscopy (DISE). Sleep Breath, 18, 453-465 (2014).

3. Randerath, W. J. et al. Non-CPAP therapies in sleep apnoea. Eur Resp J, 37 (5), 1000-1028 (2011).

4. Sutherland, K. et al. Awake multimodal phenotyping for prediction of oral appliances treatment outcome. J Clin Sleep Med, 14 (11), 1879-1887 (2018).

5. Carberry, J. C., Amatoury, J. \& Eckert, D. J. Personalized management approach for OSA. Chest, 153 (3), 744-755 (2018).

6. Ramar, K. et al. Clinical practice guideline for the treatment of obstructive sleep apnea and snoring with oral appliance therapy: an update for 2015. J Clin Sleep Med, 11 (7), 773-827 (2015).

7. Moorees, C. F. \& Kean, M. R. Natural head position, a basic consideration in the interpretation of cephalometric radiographs. Am J Phys Anthropol, 16, 213-234 (1958).

8. Pliska, B. T., Nam, H., Chen, H., Lowe, A. A. \& Almeida, F. R. Obstructive sleep apnea and mandibular advancement splints: occlusal effects and progression of changes associated with a decade of treatment. J Clin Sleep Med, 10 (12), 1285-1291 (2014).

9. Gagnadoux, F. et al. Titrated mandibular advancement versus positive airway pressure for sleep apnoea. Eur Respir J, 34 (4), 914-920 (2009).

10. Phillips, C. L. et al. Health outcomes of continuous positive airway pressure versus oral appliance treatment for obstructive sleep apnea: a randomized controlled trial. Am J Respir Crit Care Med, 187 (8), 879-887 (2013).

11. Ngiam, J., Phil, M. \& Cistulli, P. Think before sinking your teeth into oralappliance therapy. Journal of Clinical Sleep Medicine. 10, No, 12, 1293-1294 (2014).

12. Alessandri-Bonetti, G., Ippolito, D. R., Bartolucci, M. L., D'Antò, V. \& Incerti-Parenti, S. Cephalometric predictors of treatment outcome with mandibular advancement devices in adult patients with obstructive sleep apnea: a systematic review. Korean J Orthod, 45 (6), 308-321 (2015).

13. Nishio, Y. et al. Treatment outcome of oral appliance in patients with REM-related obstructive sleep apnea. Sleep Breath, https://doi.org/10.1007/s11325-019-01966-5 (2019).

14. Guarda-Nardini, L., Manfredini, D., Mion, M., Heir, G. \& Marchese-Ragona, R. Anatomically based outcome predictors of treatment for obstructive sleep apnea with intraoral splint devices: a systematic review of cephalometric studies. J Clin Sleep Med, 11 (11), 1327-1334 (2015).

15. Shen, H. L., Wen, Y. W., Chen, N. H. \& Liao, Y. F. Craniofacial morphologic predictors of oral appliance outcomes in patients with obstructive sleep apnea. J Am Dent Assoc, 143 (11), 1209-1217 (2012).

16. Marklund, M., Franklin, K. A., Stenlund, H. \& Persson, M. Mandibular morphology and the efficacy of a mandibular advancement device in patients with sleep apnoea. Eur J Oral Sci, 106 (5), 914-921 (1998).

17. Mostafiz, W. et al. Influence of oral and craniofacial dimensions on mandibular advancement splint treatment outcome in patients with obstructive sleep apnea. Chest, 139 (6), 1331-1339 (2011). 
18. Ng, A., Darendeliler, M., Petocz, P. \& Cistulli, P. Cephalometry and prediction of oral appliance treatment outcome. Sleep Breath, 16 (1), 47-58 (2012).

19. Mehta, A., Qian, J., Petocz, P., Darendeliler, M. A. \& Cistulli, P. A. A randomized, controlled study of a mandibular advancement splint for obstructive sleep apnea. Am J Respir Crit Care Med, 163 (6), 1457-1461 (2001).

20. Hoekema, A. et al. Predictors of obstructive sleep apnea-hypopnea treatment outcome. J Dent Res, 86 (12), 1181-1186 (2007).

21. Woods, M. Sagittal mandibular changes with overbite correction in subjects with different mandibular growth directions: late mixed-dentition treatment effects. Am J Orthod Dentofacial Orthop, 133 (3), 388-394 (2008).

22. Lin, S. W. et al. Three-dimensional photography for the evaluation of facial profiles in obstructive sleep apnea. Respirology, 23 (6), 618-625 (2018).

23. Gonçalves, J. R. et al. Airway space changes after maxillomandibular counterclockwise rotation and mandibular advancement with TMJ Concepts ${ }^{\circledR}$ total joint prostheses: three-dimensional assessment. Int J Oral Maxillofac Surg, 42 (8), 1014-1022 (2013).

24. Heidsieck, D. S. P., Koolstra, J. H., de Ruiter, M. H. T., Hoekema, A. \& de Lange, J. Biomechanical effects of a mandibular advancement device on the temporomandibular joint. J Craniomaxillofac Surg, 46 (2), 288-292 (2018).

25. Ecija Navarro, R. et al. Relationship between craniofacial growth and the airway. J Anat, 222 (6), 273-304 (2013).

26. Crovetto, Martínez, R. C. Estudio de la eficacia y seguridad de un dispositivo intraoral de avance mandibular en pacientes roncadores habituales con síndrome de apnea-hipopnea de carácter leve-moderado [doctoral thesis]. ISBN: 978-84-6941040-0(2010).

27. Consenso, N. del, S.A.H.S. Arch Bronconeumol41, Suppl. 4, 68-74(2005).

28. Cistulli, P. A., Gotsopoulos, H., Marklund, M. \& Lowe, A. A. Treatment of snoring and obstructive sleep apnea with mandibular repositioning appliances. Sleep Med Rev, 8 (6), 443-457 (2004).

29. Gregoret, J. Ortodoncia y cirugíaortognática Diagnosticoyplanificación.Ed. Espaxs. Publicaciones Médicas Barcelona, 12, 227-232 (2000).

30. Gottsauner-Wolf, S., Laimer, J. \& Bruckmoser, E. Posterior Airway Changes Following Orthognathic Surgery in Obstructive Sleep Apnea. J Oral Maxillofac Surg. 76(5), 1093.e1-1093.e21(2018).

\section{Figures}

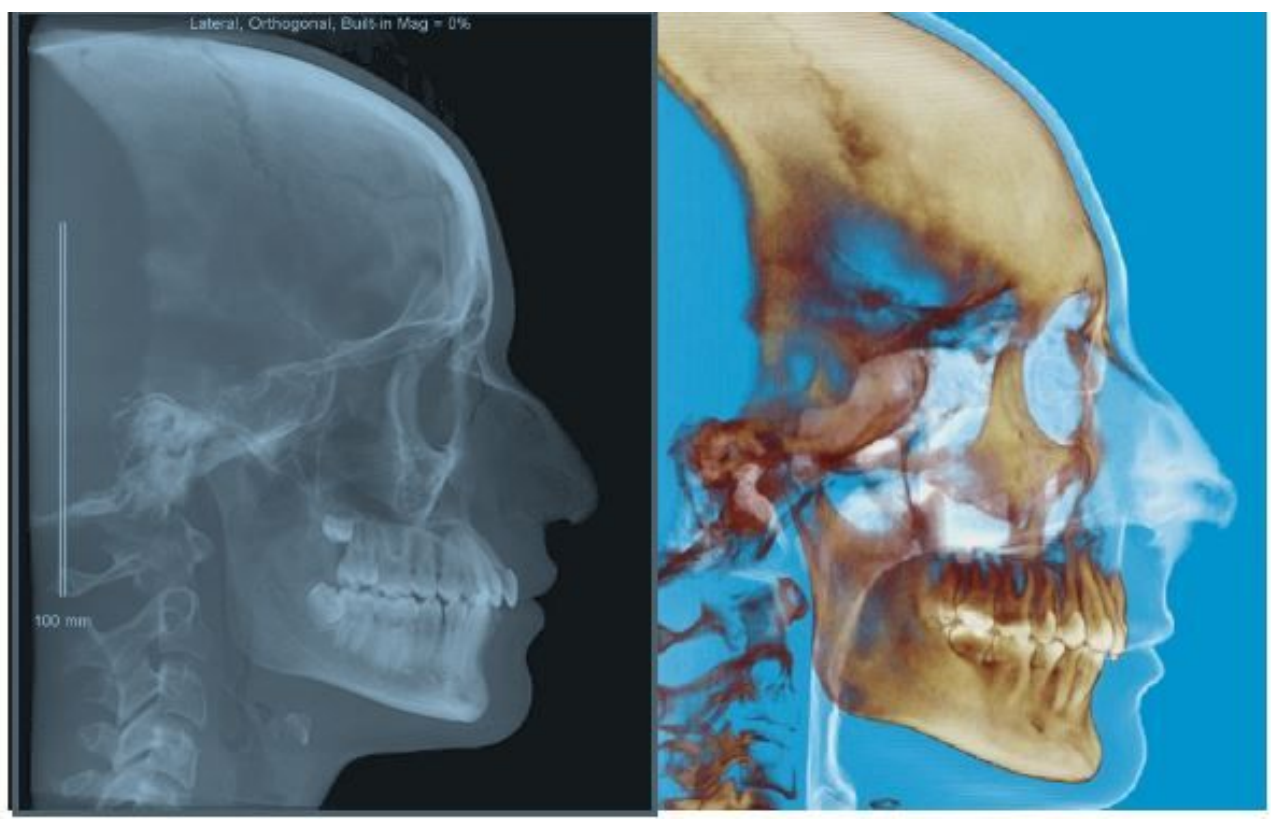

Figure 1 


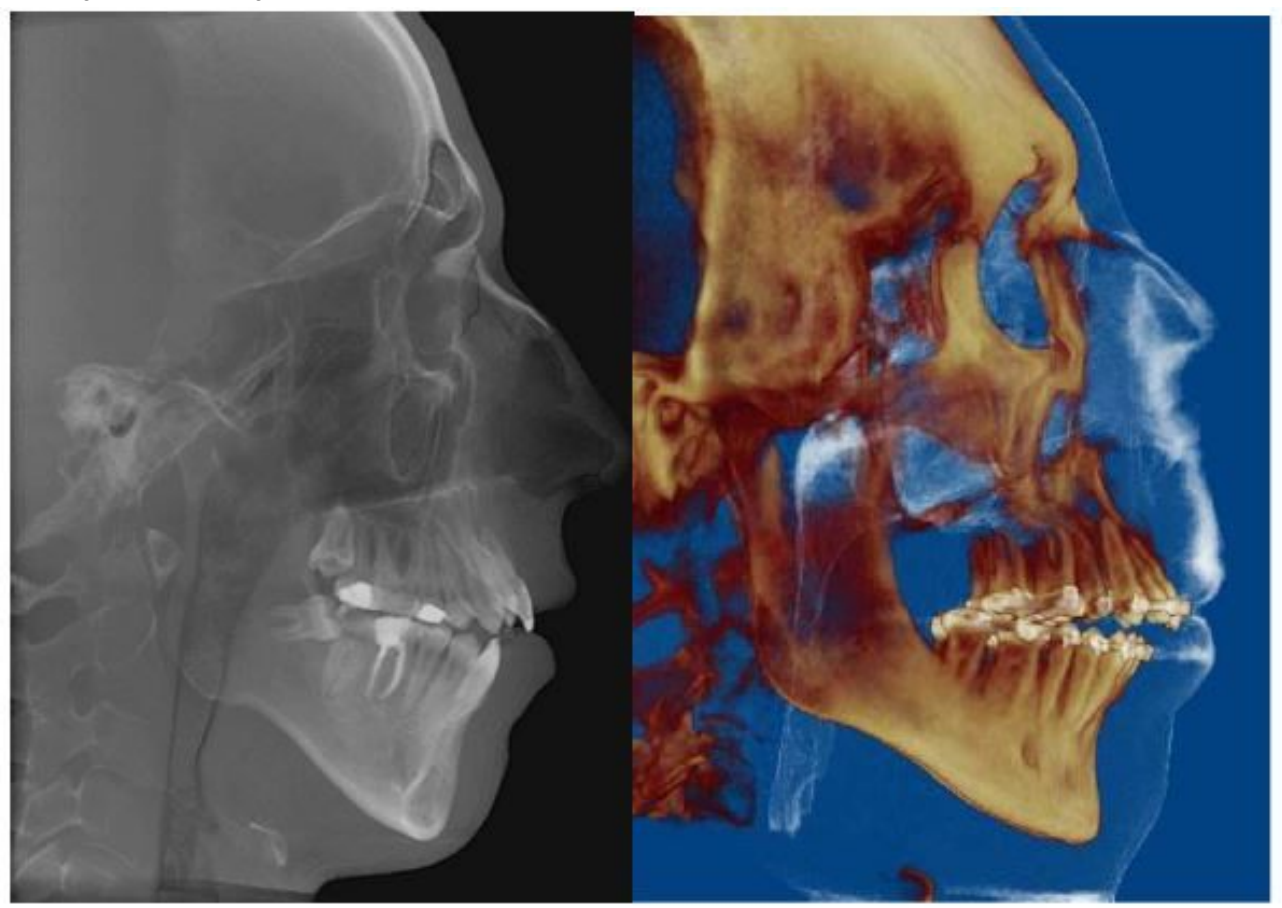

\section{Figure 2}

\section{Dolichofacıal Biotype}

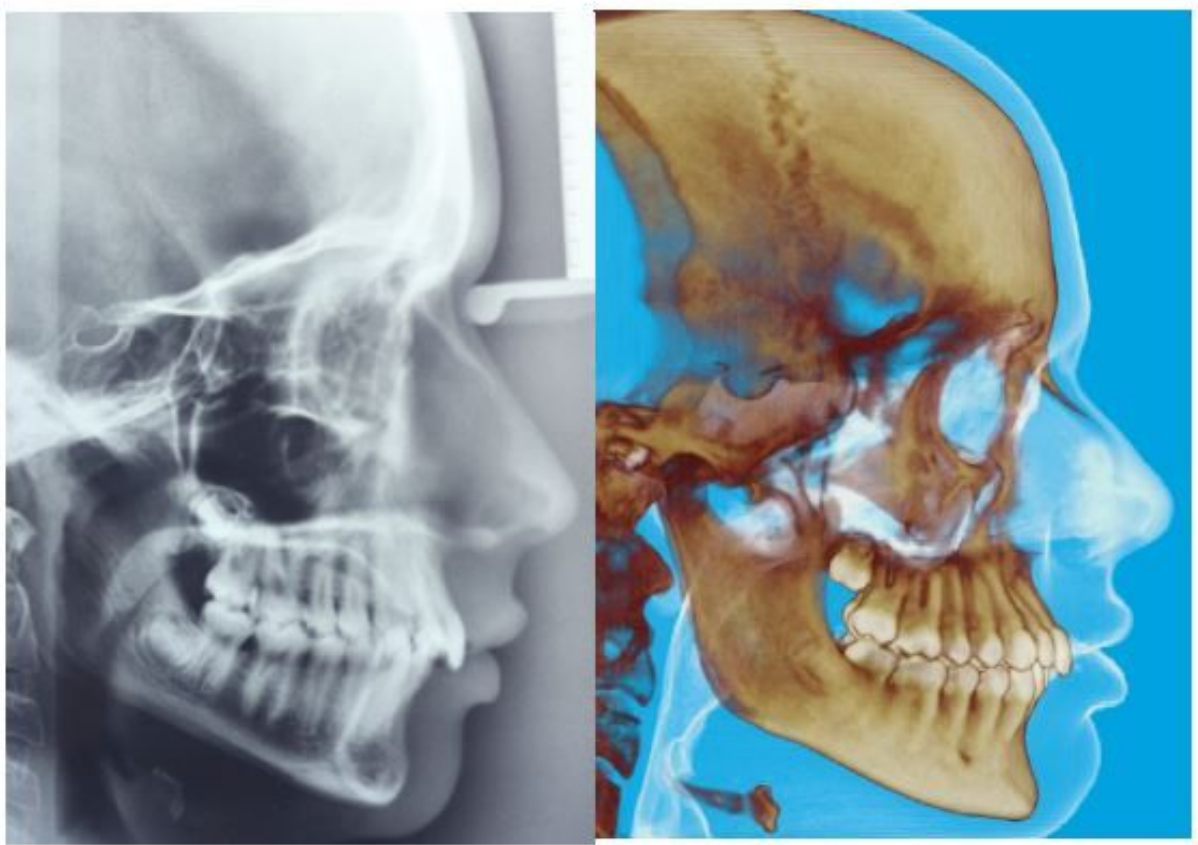

\section{Figure 3}

Mesofacial Biotype 


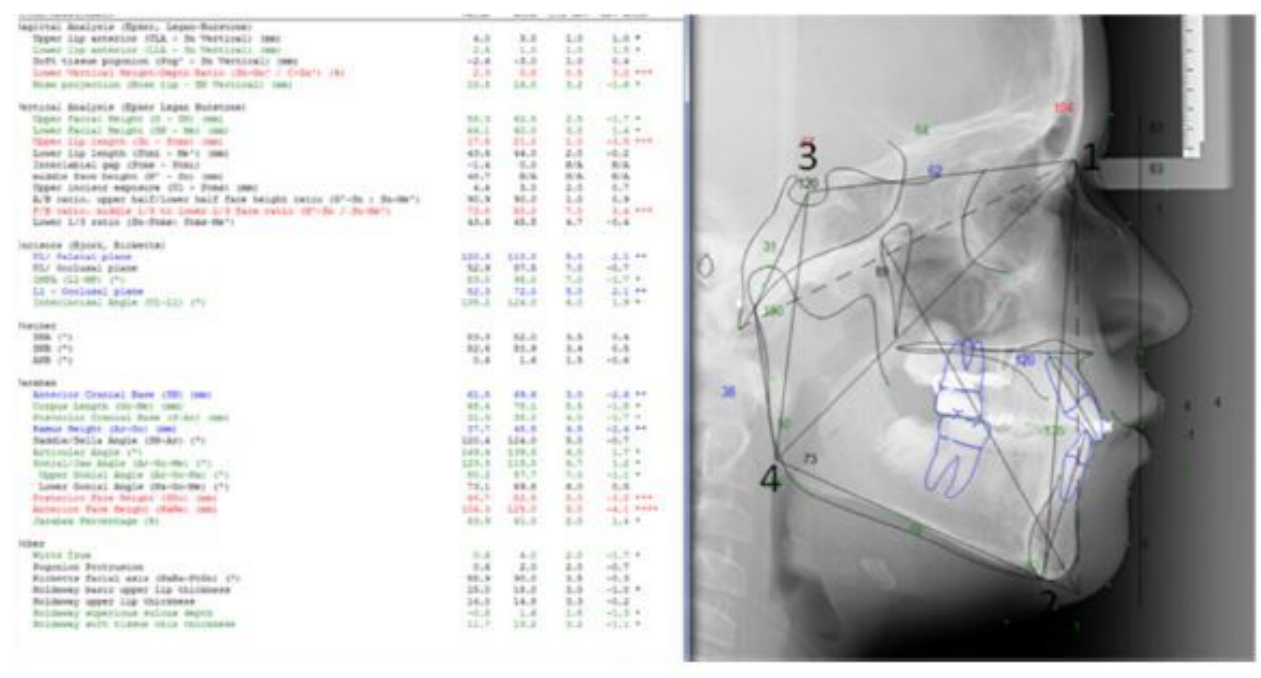

\section{Figure 4}

The cephalometric points. The cephalometric points. Nasion (Na)1: Upper part of the frontonasal suture. Menton (Me)2: Lower point of the mandibular symphysis. Sella (S)3: Centre of the sellar region located in the sphenoid bone. Gonion (Go)4: Lower and posterior point of the gonion angle.
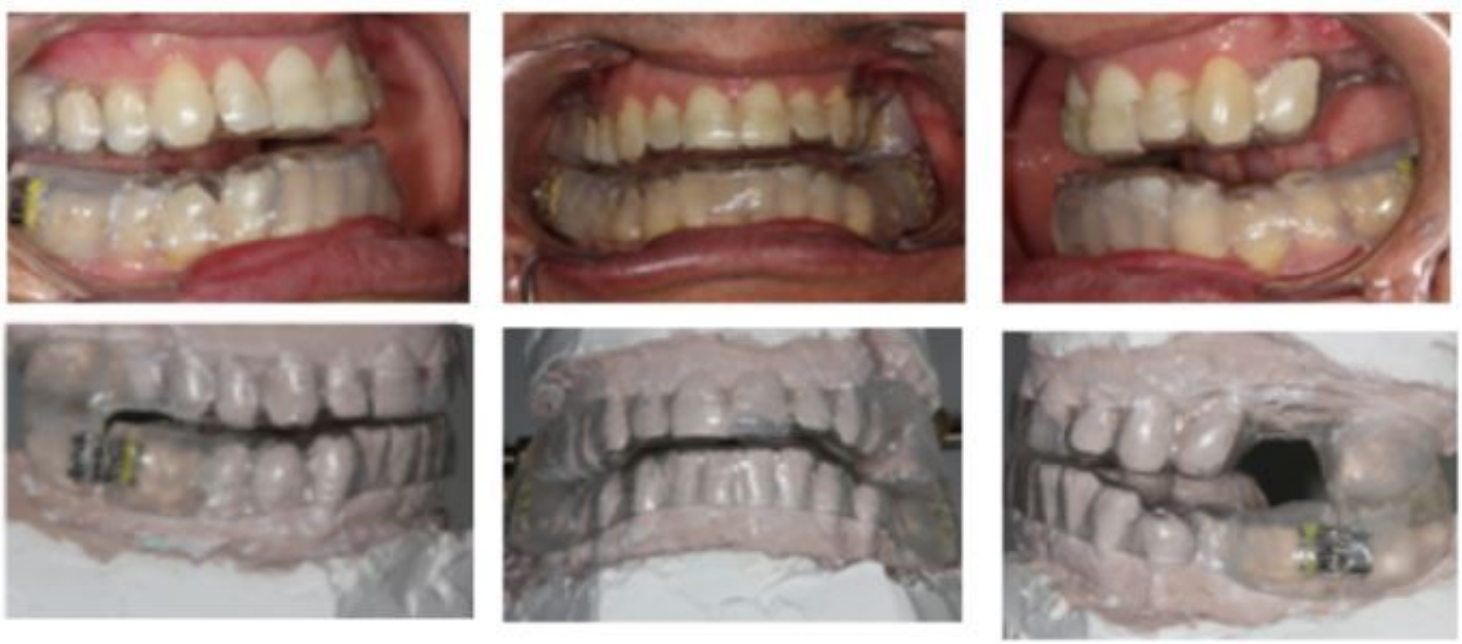

\section{Figure 5}

Mandibular Advancement Device 